Thorax (1973), 28, 295.

\title{
Ultrasonic identification of sources of gaseous microemboli during open heart surgery
}

\author{
E. G. GALLAGHER and D. T. PEARSON \\ Regional Cardiothoracic Unit, Shotley Bridge General Hospital, Consett, Co. Durham
}

\begin{abstract}
An ultrasonic transducer was used to detect gaseous microemboli during open heart surgery. When placed over the carotid artery of patients during surgery it was recognized that gaseous emboli were released into the systemic circulation following recognizable surgical procedures and from the oxygenator during bypass. Fixation of the transducer on the arterial return from the oxygenator demonstrated that the two types of disposable bubble oxygenators and disc oxygenators tested delivered microbubbles in the arterial blood. Some factors affecting the number of bubbles released were recognized and are discussed. Case reports of two patients who received large volumes of gaseous microemboli from different sources are presented.
\end{abstract}

Cerebral dysfunction has been reported to occur frequently following cardiac surgery, especially in those operations involving the use of cardiopulmonary bypass (Leading article, Lancet, 1964). Although the use of cardiopulmonary bypass has allowed significant advances to take place in the field of cardiac surgery, most commonly used oxygenators alter the blood in a way which leads to damage of the perfused tissues. The brain would appear to be particularly susceptible to damage in this context, and many reports indicate a wide variety of disturbances in cerebral function ranging from mild delirium and psychosis to overt focal and diffuse neurological deficits (Blachy and Starr, 1964 ; Sachdev, Carter, Swank, and Blachly, 1967 ; Ehrenhaft and Claman, 1961 ; Gilman, 1965 ; Tufo, Ostfeld, and Shekelle, 1970).

Many investigators present evidence that embolization of particulate matter is responsible for alterations in cerebral function. Emboli of fat (Caguin and Carter, 1963 ; Evans and Wellington, 1964), calcium (Baglio and Hunter, 1959), antifoam (Cassie, Riddell, and Yates, 1960), denatured protein (Lee et al., 1961), and aggregated blood elements (Osborn et al., 1970) have been implicated as aetiological agents in depression of cerebral function when cardiopulmonary bypass is used during cardiac surgery. The clinical use of a Dacron wool filter to remove abnormal solid particles from the blood has been described (Osborn et al., 1970).

The significant part played by air embolism in the alteration of myocardial and cerebral physiology during cardiac surgery is well documented
(Starr, 1960 ; Groves and Effler, 1964 ; Fishman, Carlsson, and Roe, 1969) and many techniques have been used to reduce the incidence of this complication. Gaseous microemboli originating from the pump oxygenator during cardiopulmonary bypass have been described by Selman, McAlpine, and Ratan (1967). These authors used a transparent chamber in the arterial line from the oxygenators and with the aid of magnification were able to detect these emboli. Following a preliminary report by Austen and Howry (1965) describing the use of ultrasound to detect bubbles or particulate matter during cardiopulmonary bypass, several authors have used this technique (Patterson and Kessler, 1969 ; Spencer, Lawrence, Thomas, and Sauvage, 1969 ; Lawrence, McKay, and Sherensky, 1971; Lichti, Simmons, and Almond, 1972). As well as abnormal particulate matter being implicated in the aetiology of cerebral complications other factors may be involved. A greater incidence of cerebral dysfunction has been described following a prolonged bypass, a low mean arterial pressure on bypass, and in older patients (Tufo et al., 1970). More recently, Sanderson, Wright, and Sims (1972) reported a reduced incidence of brain damage in dogs following the use of a pulsatile blood flow during extracorporeal circulation compared with the more conventional non-pulsatile flow.

We report our experience in the detection of gaseous microemboli during open heart surgery under cardiopulmonary bypass using a commercially available ultrasonic blood flow detector and an evaluation of the possible part played by the 
varying sources of these emboli in the overall picture of cerebral dysfunction following open heart surgery.

\section{TECHNIQUE}

A transcutaneous Doppler ultrasonic blood flow detector ${ }^{1}$ was used to detect gaseous microemboli. A piezoelectric crystal produces a $2 \mathrm{MHz}$ beam of ultrasound which is directed at an angle through the skin, subcutaneous tissue, and blood vessel. The particulate elements in the blood shift the frequency of the transmitted signal by an amount directly proportional to the component of velocity along the axis of the beam. The shifted frequencies, detected by a second crystal adjacent to the first, are amplified, demodulated, and presented as an audible signal through a loud speaker. A gas-blood interface produces excellent acoustic refiection. When the ultrasonic beam strikes a moving bubble a distinctive and characteristic signal is heard above the background blood flow signal.

The transducer was fixed by adhesive strapping over the left carotid artery of patients under investigation. Olive oil was used for acoustic coupling and optimal position of the transducer was indicated by maximal

1 Sonicaid Model D.205, Sonicaid Limited, Nyetimber, Bognor Regis, Sussex. blood flow signals heard through the loud speaker. The left carotid artery was chosen so as to avoid interference by ventilator and intravenous therapy tubing which lay to the right of the patient's head. The transducer, mounted in a Perspex block at an angle of $45^{\circ}$ to the direction of flow, could be clamped over the $\frac{3}{8}$ inch internal diameter tubing of the arterial line leading from the oxygenator during bypass. Angulation of the transducer head in this way produced the most satisfactory signal (Fig. 1).

To assist in the graphic display of gaseous microemboli an electronic circuit, designed to minimize the lower frequency signal due to blood flow yet $\omega$ permitting the higher frequency signals of gaseous io emboli to be displayed, was made. The Doppler of output signal from the Sonicaid was passed to an active high-pass filter which has alternative cut-off frequencies of $1.6 \mathrm{kHz}$ and $3.1 \mathrm{kHz}$. It was necessary $z$ to be able to change the characteristics of the filter as the position of the transducer was altered with respect to the direction of flow in the carotid artery and arterial line from the pump oxygenator. This positional change affects the Doppler frequency shift of both bubbles and blood flow. The filter could be bypassed for demonstration purposes.

The signal was then passed through an operational amplifier whose feedback resistor may be selected

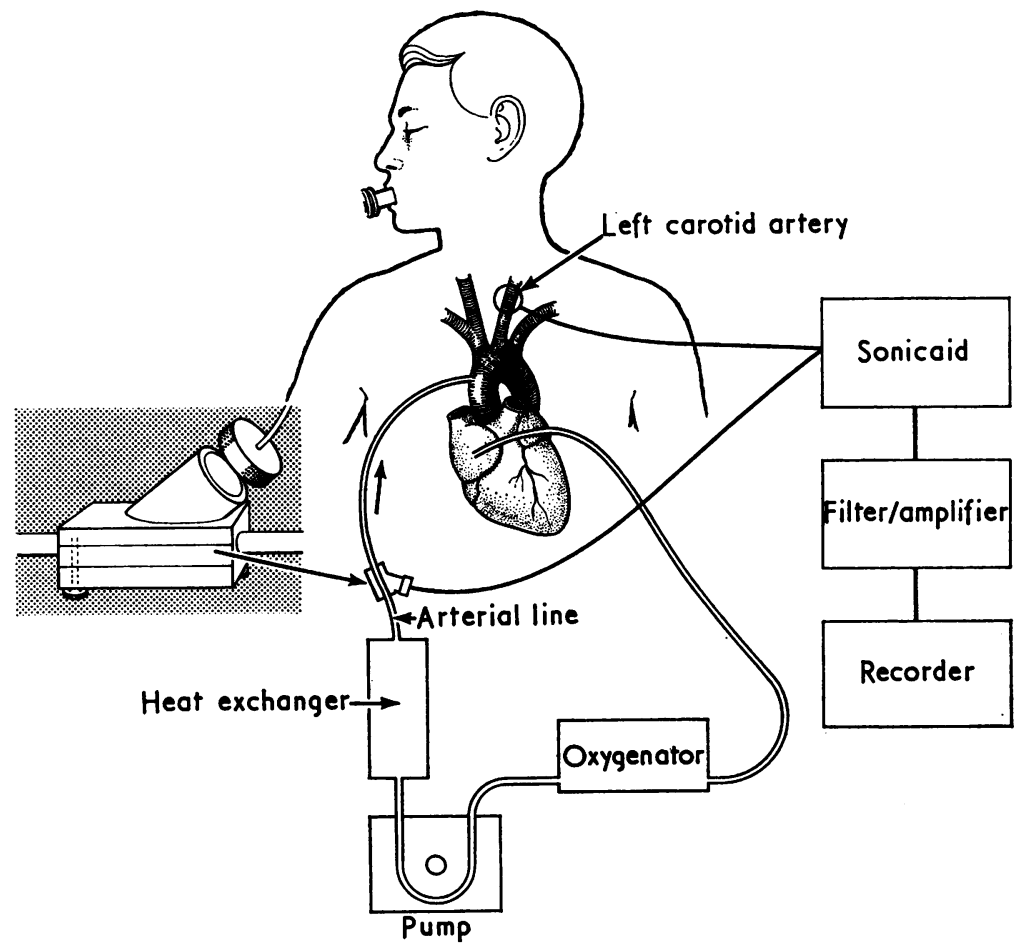

FIG. 1. Diagrammatic representation of circuit used during study. Inset shows technique of fixed transducer to $\frac{3}{8}$ inch arterial line. 
to give a gain of $0,5,10$, and 30 approximately with respect to the size of the signal. Finally, to make the signal more acceptable to the Mingograf recorder used for display, a low-pass resistor capacitor filter was inserted.

The efficiency of detection of gaseous microemboli by the ultrasonic transducer was tested in an in vitro experiment using a roller pump and disc oxygenator, the arterial and venous lines being connected in a closed loop. The circuit was primed with time-expired acid-citrate-dextrose (ACD) whole blood. Without rotation of the discs but with circulation of the blood at a flow rate of 4 litres/minute satisfactory elimination of the blood flow signal from the arterial line of the pump oxygenator using the $3 \cdot 1 \mathrm{kHz}$ high-pass filter could be achieved (Fig. 2a). Similar suppression of the blood flow signal, with the transducer over the carotid artery, using the 1.6 $\mathrm{kHz}$ filter is also shown (Fig. 2b).

Gaseous microemboli were generated by electrolysis and signals were easily detected after a time delay which allowed them to be carried past the transducer head by the blood flow (Fig. 3). Priming of the circuit with incompatible blood showing macroscopic agglutination of the red cells, or the introduction of a fat emulsion, did not produce any high-frequency signals above that of the flow of blood past the transducer.

These experiments indicate that the present transducer, with suitable electronic manipulation of blood flow signals, is able to detect gaseous microemboli in a pulsatile blood flow and detection of particulate microemboli is beyond the scope of the instrument.

Estimation of the size of bubbles with this technique is difficult. Patterson and Kessler (1969) found that by dropping plastic microspheres of known diameter into a saline-filled detecting chamber the smallest particle size that could be detected using a $5 \mathrm{MHz}$ transducer was 50 microns. Larger particles produced larger signals, and if two particles were present at the same time their amplitude was summed but only one signal was recorded. The sensitivity of an ultrasonic transducer is directly proportional to the frequency of the sound, and on this basis the $2 \mathrm{MHz}$ device used in these experiments would detect microemboli greater than 125 microns. The overall pattern of signals displayed at maximum amplification provided an indication of the quantity of gaseous microemboli passing the transducer.

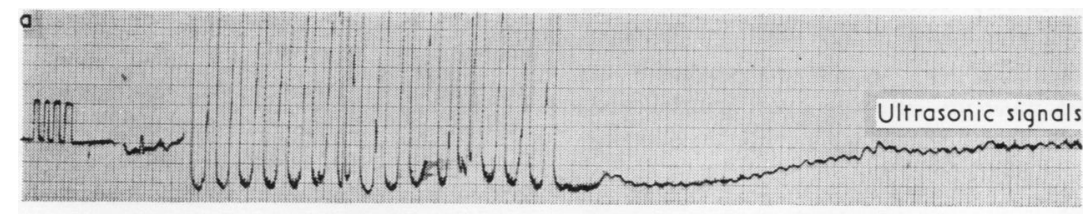

b

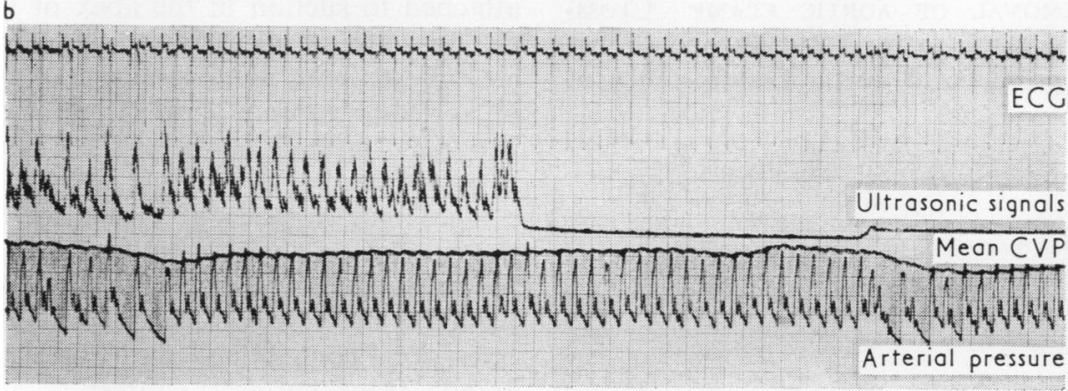

FIG. 2. Effect of $3 \cdot 1 \mathrm{kHz}$ and $1.6 \mathrm{kHz}$ high-pass filter on pulsatile blood flow signal generator (a) when transducer is placed on arterial return from oxygenator and (b) with transducer on left carotid artery.

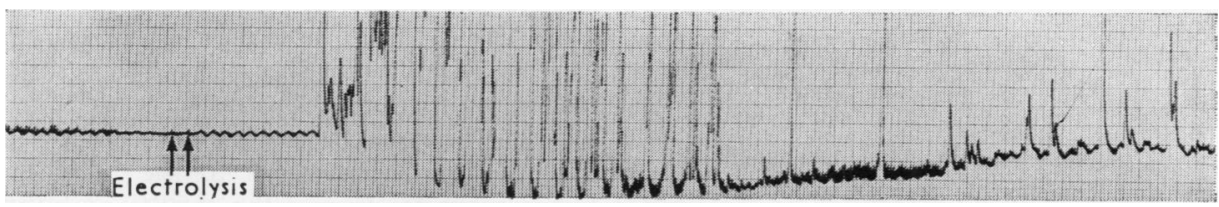

FIG. 3. Ultrasonic detection of microbubbles generated by electrolysis in an in vitro experiment using a disc oxygenator primed with blood without rotation of discs. 


\section{RESULTS}

Placement of the ultrasonic transducer over the left carotid artery gives an indication of gaseous microemboli entering the cerebral circulation by this route. Detailed observation of many patients having open heart surgery for a wide variety of congenital and acquired heart disease suggests that these emboli can originate during recognized surgical manoeuvres and from the pump oxygenator.

\section{SOURCES OF 'SURGICAL' GASEOUS EMBOLI}

CANNULATION OF AORTA Cannulation of the ascending aorta before the start of cardiopulmonary bypass may admit gaseous emboli into the systemic circulation (Fig. 4a). Even though the cannula is primed with saline beforehand a small quantity of air can be injected during its insertion. The number of gaseous emboli would appear to be independent of the level of the systemic arterial pressure at the time of insertion of the cannula.

CANNULATION OF RIGHT ATRIUM Insertion of caval cannulae through the right atrial wall in the presence of an atrial septal defect may result in systemic arterial gaseous emboli even in the presence of a left-to-right shunt at atrial level (Fig. $4 b)$.

FOLLOWING REMOVAL OF AORTIC CLAMP Crossclamping of the aorta is used during open heart surgery in the presence of aortic incompetence of

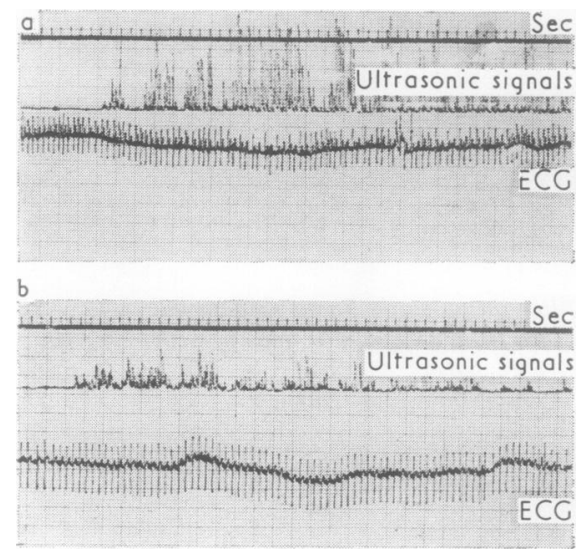

FIG. 4. Gaseous microemboli detected in left carotid artery during (a) cannulation of the ascending aorta and (b) cannulation of the right atrium in the presence of an atrial septal defect. a degree which hinders technically the replacement of the mitral valve. It may also be used to provide maximal visibility and relaxation of the heart during closure of a ventricular septal defect. It is a prerequisite of aortic valve surgery. Air may collect between the aortic clamp and the aortic valve, and even when the root of the aorta is vented through the aortic suture line or by aspiration, using a wide-bore needle, gaseous emboli may enter the systemic circulation when the clamp is removed. The occurrence of myocardial ischaemia demonstrated electrocardiographically following removal of the aortic clamp is indirect evidence of coronary artery gaseous embolism.

DURING CLOSED MITRAL VALVOTOMY During closed mitral valvotomy both digital exploration of the valve and insertion of the dilator through the left ventriculotomy may introduce gaseous emboli into the systemic circulation.

FOLLOWING RESTORATION OF EFFECTIVE HEART ACTION ON COMPLETION OF SURGERY Following cardiotomy for an open septum or during the exposure of left-sided cardiac valves, cardiac propulsion is prevented until the heart is filled with blood, air pockets are displaced, and bubbles trapped in muscular trabeculae are finally removed. Many techniques are used including ventricular fibrillation, needle venting of the aorta, and left ventriculotomy with insertion of a drain attached to suction in the apex of the left ventricle. In spite of all attempts to remove entrapped air, all patients demonstrate a variable amount of systemic gaseous emboli when effective heart action is restored at the end of cardiopulmonary bypass (Fig. 5).

The total number of gaseous emboli entering the circulation during cannulation of the heart and removal of the aortic clamp is relatively small. Residual air trapped in the heart at the end of operation contributes the greatest number of emboli from 'surgical' sources.

\section{GASEOUS MICROEMBOLI ORIGINATING FROM PUMP OXYGENATOR}

The transducer, mounted in the Perspex block at $45^{\circ}$ to the direction of blood flow, was clamped over the $\frac{3}{8}$ inch diameter PVC tubing of the arterial line from the oxygenator distal to the roller pump and heat exchanger. It was found that all oxygenators deliver variable quantities of gaseous microemboli to the patient, but it is convenient to discuss the results of bubble detection in the two main types of oxygenators, bubble dispersion oxygenators and disc oxygenators. 


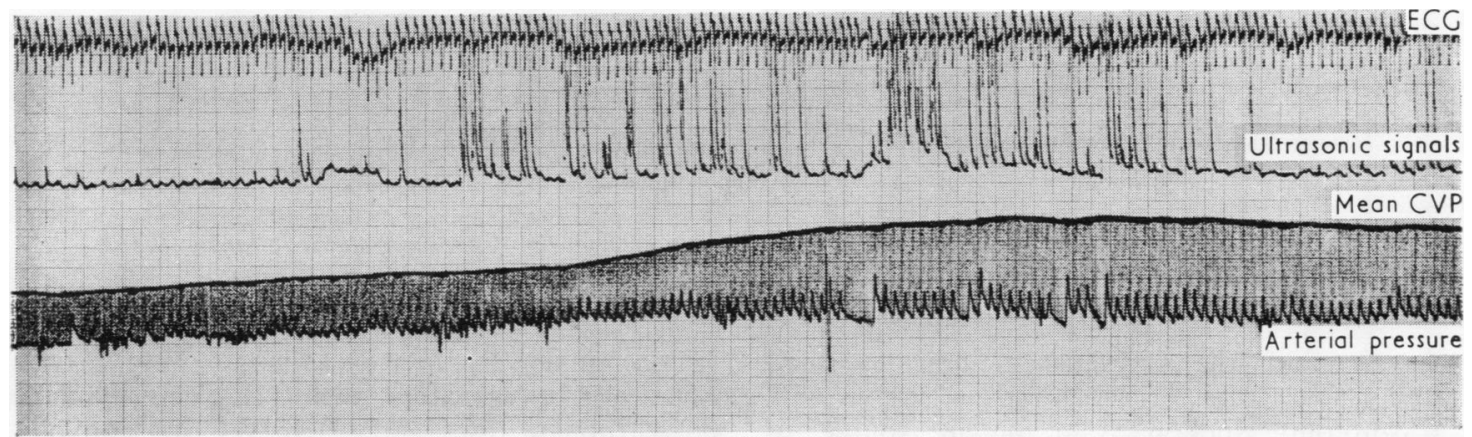

FIG. 5. Gaseous microemboli detected in left carotid artery on resumption of heart action following bypass.

\section{BUBBLE DISPERSION OXYGENATORS}

Bubble oxygenators of the Travenol type were mainly used during the study, though a limited experience with Rygg disposable oxygenators was gained. There is no reason to believe that factors influencing release of microemboli (Table) differ in the two types under consideration, even though the quality and quantity of gaseous microemboli may be different.

\section{T A B L E}

FACTORS AFFECTING RELEASE OF MICROBUBBLES FROM OXYGENATOR

\begin{tabular}{c|c}
\hline Bubble Dispersion Oxygenator & Disc Oxygenator \\
\hline $\begin{array}{c}\text { Addition of cold blood or fluid to oxygenator } \\
\text { Low blood in the oxygenator }\end{array}$ \\
\begin{tabular}{c|c} 
Increasing the ratio of gas flow \\
to blood flow \\
Agitation of oxygenators the rate of disc \\
rotation
\end{tabular} \\
$\begin{array}{c}\text { High level of blood in } \\
\text { oxygenator }\end{array}$ \\
\hline
\end{tabular}

Precirculation of the priming fluid of the pump oxygenator has been advocated to eliminate bubbles of gas from the circuit. When the arterial and venous lines of the oxygenator are united to form a ductus loop during the precirculation phase prior to bypass the oxygenating column of the oxygenator can be reduced in volume by a clamp. Oxygen is not added at this time. After elimination of bubbles visible to the naked eye from the circuit, it is still possible to detect ultrasonically gaseous microemboli during this precirculatory phase. Careful observation of the Travenol oxygenator at this time when a non-blood prime is used reveals visible bubbles entering the settling chamber due to turbulence as the fluid flows from the defoaming chamber. Many of these rise to the surface but others are carried into the helix and enter the arterial circulation. A similar situ- ation exists in the Rygg oxygenator but to a lesser extent. Bubbles retained in the circuit following precirculation can be detected entering the systemic circulation at the start of bypass.

When the level of fluid in the settling chamber of both the Travenol and Rygg oxygenators is low an increase in gaseous microemboli can be detected. In the case of the Travenol oxygenator, this rise in microemboli released occurs even before the safe operating level, indicated by an arrow on the oxygenator, is reached. Below this level massive quantities of gaseous microemboli escape into the arterial line. A virtual absence of gaseous emboli is achieved only when the level of fluid in the settling chamber rises to the lower border of the defoaming chamber. At this level turbulence is reduced and the passage of the blood through the oxygenator is slowed. This feature is more marked in the current Travenol 6LF and 3LF (U310) versions compared with the 2LF (U330) and 1LF (U340) oxygenators.

During surgery blood aspirated from the pericardium and heart is returned to the oxygenator as an air-blood mixture. This blood may contain particulate emboli of calcium, fat, and other debris. The bubbles created by suction are qualitatively different from those generated in the oxygenating column of the oxygenator and consist mainly of nitrogen, a relatively insoluble gas. Various cardiotomy reservoirs have been designed, incorporating filters and defoaming chambers, in an attempt to remove particulate matter and bubbles. The admission of a volume of blood collected over a short period from any one of these reservoirs to the oxygenator results, after a time delay sufficient to allow the blood to traverse the oxygenator, in an increase in the incidence of gaseous microemboli in the arterial line detected by the ultrasonic transducer (Fig. 6). The persistence of these microbubbles after passage through both the defoamer in the cardiotomy 


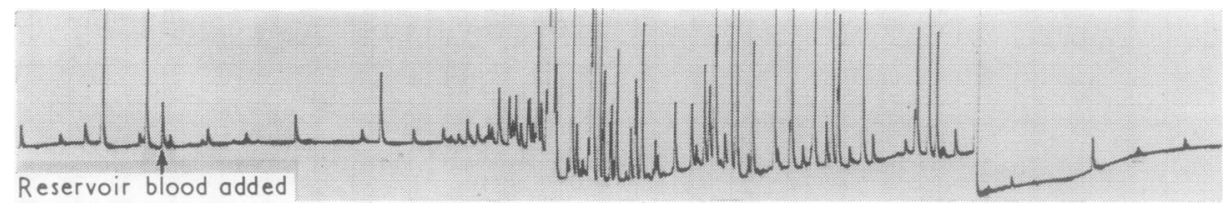

FIG. 6. Increase in number of microbubbles detected in arterial line from oxygenator following the admission of $300 \mathrm{ml}$ of blood from Bentley Q120 cardiotomy suction reservoir to oxygenator.

reservoir and the oxygenator indicates their stability.

Cardiotomy suction is a potent source of gaseous microemboli even when clinically accepted reservoirs are used. These emboli are potentially more dangerous than the emboli originating from the oxygenator because of the decreased solubility of nitrogen compared with oxygen in blood. It is for this reason that flooding of the surgical field with carbon dioxide has been advocated since this gas is said to be more soluble than air.

During cardiopulmonary bypass many gaseous microemboli remain attached to the walls of the oxygenator. Agitation of the oxygenator can release these into the arterial blood as indicated by an increase in echoes detected. Once bypass is established, care should be exercised to avoid interference with the walls of the oxygenator.

The rapid addition of store blood at $4^{\circ} \mathrm{C}$ to the oxygenator or cardiotomy reservoir increases the incidence of microbubbles detected. It is for this reason that in clinical practice it is advisable to pass all fluids through a warming coil before addition to the oxygenator circuit so that the decrease in solubility of the dissolved gases at higher temperatures does not allow gaseous emboli to be generated in the circuit as the fluid is rapidly warmed in the heat exchanger.

It is difficult to demonstrate clinically that a rise in the ratio of gas flow to blood flow increases the numbers of microemboli released. The increase in emboli detected towards the completion of surgery as the venous return from the patient to the oxygenator is reduced, the gas flow remaining constant, may be a function of a gas flow/blood flow ratio rise. It can, however, be demonstrated experimentally that increasing this ratio above that required clinically does increase the number of bubbles released.

\section{DISC OXYGENATORS}

The factors involved in the production of gaseous microemboli by disc oxygenators are shown in the Table.
Preliminary in vitro experiments were carried $\overrightarrow{\vec{x}}$ out using oxygenators with (1) electrodynamic polycarbonate discs and (2) Kay-Cross convolu- $\omega$ ted steel discs coated with silicone. The oxygena- if tors were connected through a roller pump and circulated with heparinized and recalcified ACD 을 blood through a ductus loop. A venous reservoir was not included in the circuit. When the blood was circulated at a flow rate of 4 litres/ minute without rotation of the discs, no microbubbles could be detected ultrasonically. As soon as disc rotation was begun, microbubbles could be detected in the arterial line and the numbers steadily increased as the rate of disc rotation increased (Fig. 7). It is significant that the discharge of microemboli began at disc revolution rates below that required for adequate oxygenation during perfusion. Microbubbles ceased to be produced when the discs were stationary, allow-
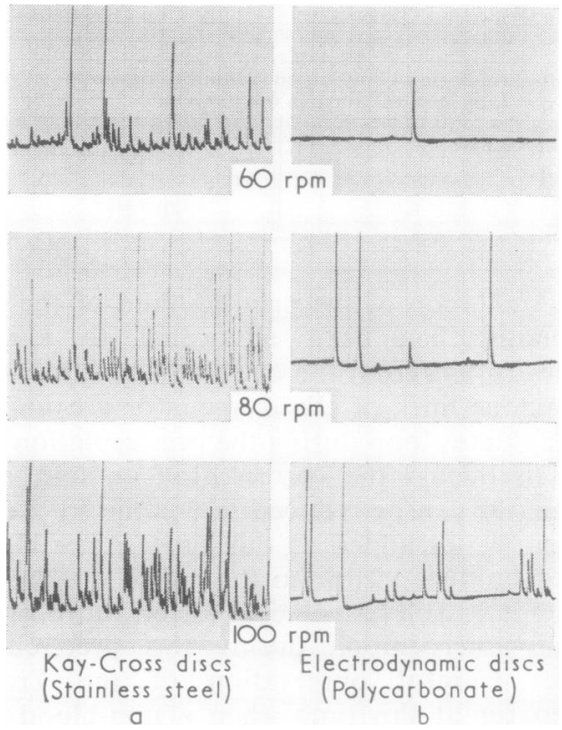

FIG. 7. Effect of increasing the rate of disc rotation on production of microbubbles in (a) Kay-Cross disc oxygenator using stainless steel discs and (b) electrodynamic polycarbonate discs. 
ing for a suitable time interval for clearing of the emboli from the circuit.

Naked-eye observation of rotating discs in a solution of $60 \%$ glycerin in water at $37^{\circ} \mathrm{C}$ (the viscosity of this solution at $37^{\circ} \mathrm{C}$ is approximately equal to that of blood at $37^{\circ} \mathrm{C}$ ) shows bubbles held under the surface of the fluid by vortices occurring between the discs (Fig. 8). The greater the rate of revolutions per minute the more deeply are these bubbles held under the surface. These are then carried by the liquid flow to the arterial outlet.

Using the circuit described above, it has been shown that the spacing of the discs plays an important part in the evolution of gaseous emboli.

The Kay-Cross stainless steel discs are $11.9 \mathrm{~cm}$ in diameter. They are mounted $4.7 \mathrm{~mm}$ apart, by means of stainless steel spacers, on a central shaft. There are 92 discs in the 21 inch disc oxygenator. It has been calculated that to provide a maximum exposure area of blood to oxygen the discs should be immersed to a depth of $4 \cdot 1 \mathrm{~cm}$. At a disc rate of 120 revolutions per minute, the rate generally employed, $128 \mathrm{~m}^{2}$ of filmed blood is exposed to oxygen per minute.

When the distance between the Kay-Cross discs is doubled, by inserting a second steel spacer, a reduction in the number of microbubbles generated results. The reduced oxygenating capacity of the oxygenator thus assembled makes it unacceptable in clinical situations.
In comparison, the electrodynamic polycarbonate discs are $13.0 \mathrm{~cm}$ in diameter and are $7.0 \mathrm{~mm}$ apart. There are 57 discs in the 22 inch oxygenator. When the discs are immersed in blood to the extent recommended for the Kay-Cross steel discs and rotated at $120 \mathrm{rev} / \mathrm{min}$ the surface area of blood exposed to oxygen per minute is $139 \mathrm{~m}^{2}$. This oxygenator produces fewer microbubbles than the Kay-Cross oxygenator at corresponding blood flow and disc revolution rates.

When $12 \mathrm{~cm}$ diameter polycarbonate discs spaced at $7.0 \mathrm{~mm}$ are placed in the Kay-Cross oxygenator chamber fewer microbubbles are produced. Because of the increased spacing the number of discs was reduced, so reducing the surface area of blood exposed to oxygen.

It is recognized that a level of blood in the oxygenator which is too low or too high-reaching the level of the disc spacers-may produce frothing in the blood and should be avoided.

The turbulence produced in a venous reservoir, particularly when the level is low, introduces bubbles of air into the venous outlet of the oxygenator. This adds to the number of bubbles generated by the discs and, like the bubbles introduced through cardiotomy suction, they are nitrogen-containing bubbles.

Appraisal of disc oxygenators with ultrasound has confirmed that they produce gaseous emboli during clinical perfusions. The flow rate of gas

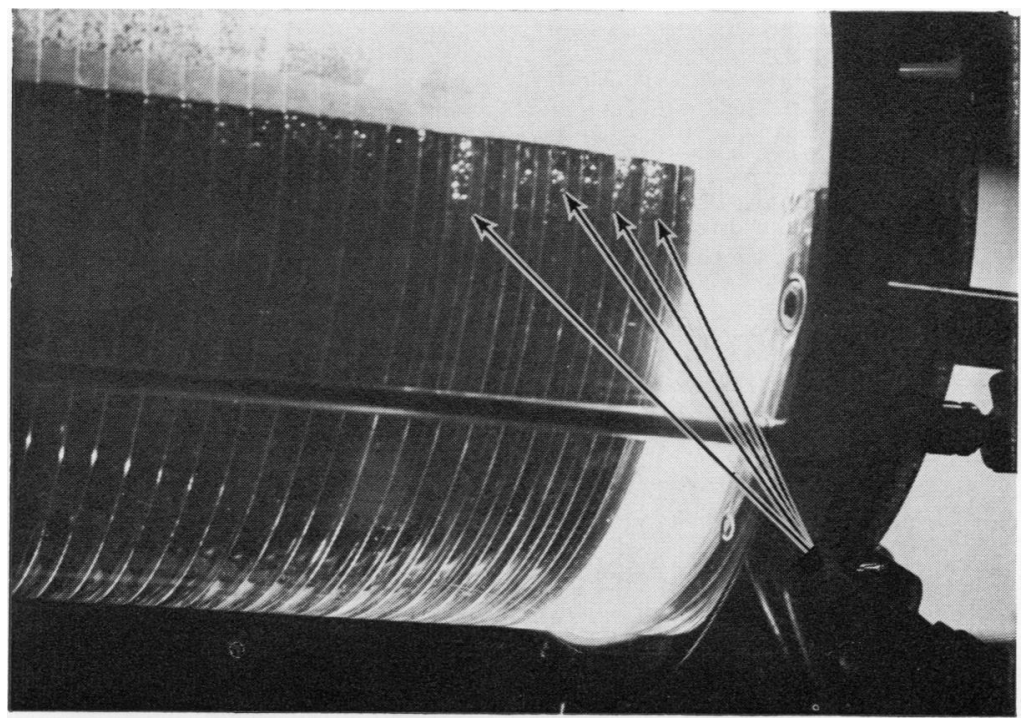

FIG. 8. Bubbles held under the surface of fluid by vortices occurring between the discs in a Kay-Cross disc oxygenator. 
into the disc oxygenator does not appear to influence microbubble formation.

Bass and Longmore (1969) suggested that microbubbles may be generated in a supersaturated solution by the negative pressure produced by the roller pump. We have tested the Sarns and Pemco pumps at various flow rates and occlusion settings but have been unable to demonstrate that microbubbles originate in the roller pumps.

It is difficult to achieve stable conditions during clinical perfusions because of variations in volumes of cardiotomy suction and the fact that oxygenators of similar design appear to vary in their ability to eliminate excess microbubbles produced. A pattern of microbubbles produced by four types of oxygenator during perfusion is shown (Fig. 9).

The following cases illustrate the possible effect of large volumes of gaseous microemboli during cardiopulmonary bypass from two different sources.

CASE 1 A 6-year-old girl had an asymptomatic atrial septal defect. A large shunt was demonstrated by cardiac catheterization and her pulmonary vascular resistance was low. The defect was closed with a Dacron patch under cardiopulmonary bypass. Following removal of left ventricular air through a vent the heart action was satisfactory and cardiopulmonary bypass was discontinued.

During bypass occasional microemboli of gas were के detected in the carotid circulation with the ultra- $\vec{O}$ sonic transducer. Following restoration of heart action increased numbers of microemboli were detected in $\vec{\omega}$ two phases. An initial phase was followed by a $\stackrel{\circ}{\circ}$ period, lasting approximately 10 minutes, during $\overrightarrow{\vec{x}}$ which few gas emboli were detected. Following this large numbers of gaseous emboli were detected and $\infty$ these continued until the patient left the operating theatre.

At the end of operation the child awoke and responded to command but the following morning she was more drowsy than expected though her circulation was good. There was a right extensor plantar response and the tone in the right arm and leg was slightly increased when compared with the $\vec{\varphi}$ left side. Some three hours later she developed $\omega$ spasmodic movements of her side leading to a generalized convulsion.

Intermittent positive pressure ventilation was started using pancuronium bromide as a muscle relaxant. She later developed tachycardia with peripheral vaso-

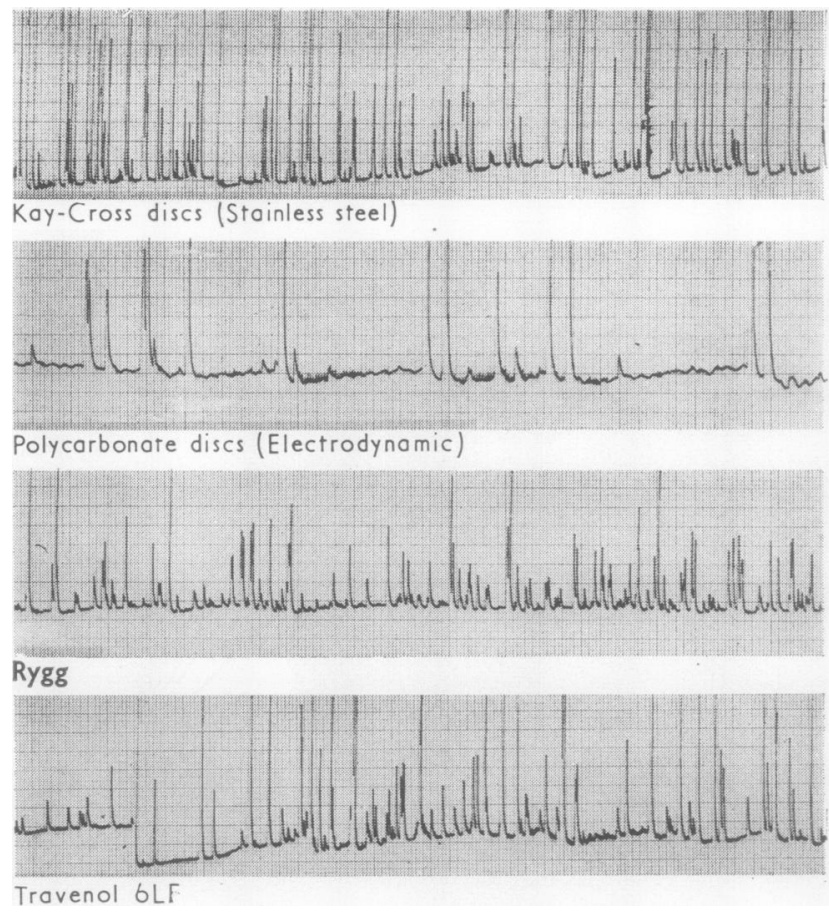

FIG. 9. Microbubbles detected in the arterial return from the oxygenator during clinical perfusion of adult patients with four oxygenators. Blood flow about 4 litres/minute. 
constriction. Supportive therapy was begun and her circulation improved. Twenty-four hours later her paralysis was reversed with neostigmine and she was found to be decerebrate. She died on the sixth day following operation without regaining consciousness.

Gross examination of the brain at necropsy showed diffuse changes; it was oedematous and the brain matter was soft and almost liquid.

CASE 2 A 62-year-old man had had two previous operations in which prosthetic aortic valves had been inserted. He was admitted for a further aortic valve replacement because of perivalvar leak.

Because of the two previous operations, dissection of the heart was difficult. Although the aorta was clamped it was very difficult to keep the heart empty of blood despite left atrial venting. This necessitated much coronary suction, resulting in large volumes of blood mixed with air being returned to the oxygenator. Although this blood passed through a cardiotomy reservoir large volumes of microbubbles traversed the oxygenator and were detected in the arterial blood returning to the patient. This situation persisted lor up to 30 minutes of bypass time.

At the end of operation the patient was unconscious although there was a slight response to tracheal suction. There was no response to pain. His limbs were hypertonic. His circulatory state was satisfactory at all times until two days before he died. He died six days after surgery without regaining consciousness.

At necropsy the brain was small and firm. On cross section there were scattered areas of infarction throughout both cerebral hemispheres.

In both cases blood pressure was well maintained during perfusion and the duration of bypass was less than one hour.

\section{DISCUSSION}

In 1914 Carrel stressed the potential hazard of systemic air embolism during surgical procedures on the left side of the heart. The use of vents (Miller et al., 1953 ; Groves and Effler, 1964), induced cardiac fibrillation (Senning, 1952 ; Nicks, 1969), flooding of the operative field with carbon dioxide (Nichols, Morse, and Hirose, 1958 ; Burbank, Ferguson, and Burford, 1965), and aspirating the veins and cardiac chambers with a needle (Taber, Maraan, and Tomatis, 1970) have reduced but not eliminated the incidence of air embolism. Using a technique of intracardiac cinephotography in animals, Padula, Eisenstat, Bronstein, and Camishion (1971) have shown that air retained by gravity and trapped by anatomic intracardiac structures is nearly all removed by the commonly used aortic and ventricular vents but that several small bubbles remained firmly adherent to the endocardial surfaces. Our findings of increased numbers of gaseous microemboli in the carotid circulation for periods of up to one hour on resumption of effective heart action confirms this point. Trapping of air in the superior pulmonary veins during bypass, described by Fishman et al. (1969), may account for the delayed release of emboli described in one patient.

In animal experiments a wide variation in tolerance to air embolism in the brain (Fries et al., 1957) and heart (Spencer, Rossi, Yu, and Koepke, 1965) was found. Surgically introduced air is, in most patients, probably insufficient to produce gross cerebral dysfunction but, when combined with gaseous microemboli from the oxygenator system over a prolonged period, it may adversely affect the outcome. The quantitative occurrence of air emboli is of the utmost importance in producing significant clinical symptoms (Lawrence et al., 1971). In this context microemboli of pure oxygen should be included. Animals which receive a slow injection of oxygen into the carotid artery demonstrated the same qualitative changes as those which received air (Fries et al., 1957). Greater attention should be focused on the pump oxygenator as a source of gaseous microemboli and every attempt should be made to eliminate them completely.

Our findings that cardiotomy suction contributed to the number of gaseous microemboli detected in the arterial line of the oxygenator are in contrast to those of Lawrence et al. (1971) but confirm the findings of Spencer et al. (1969). Most cardiotomy reservoirs incorporate a filter and defoaming substance and although they reduce the number of gaseous microemboli returning to the oxygenator the stability of these bubbles renders them difficult to eliminate completely. We cannot agree with Selman et al. (1967) that a cardiotomy blood reservoir is not essential when using a Travenol disposable oxygenator.

Precirculation of the priming fluid of the oxygenator prior to bypass, to eliminate microbubbles from the circuit, has been advocated by Selman et al. (1967). Although removing visible bubbles, microbubbles detected ultrasonically still persist.

The efficiency of oxygenation of flowing blood by gas dispersion is related to the size of the blood gas interface ; the greater the number of bubbles that can be generated from a given volume of gas the more efficient will be the oxygenation. The practical lower limit of bubble size is dictated by the ability of the oxygenator to remove excess bubbles. The improved oxygenating capacity of the Travenol disposable bubble oxygenator when the polyethylene membrane (pore size 700 microns) was replaced by a microporous ceramic 
mantle (pore size 120 microns) has been shown (Ferguson, Burbank, and Burford, 1967). Although these authors reported that the excess bubbles generated by the 120 micron ceramic mantle were eliminated from the perfusate this is contrary to our experience. The more complete elimination of excess bubbles generated by the Travenol 1,2 and 3 LF oxygenators (pore size 700 microns) as compared with the Travenol 6LF (pore size 120 microns) would suggest that adequate oxygenation and bubble elimination could be achieved using a bubble generator with a pore size in the region of 300 microns.

In the absence of any degree of coronary suction, Spencer et al. (1969) did not detect any microemboli in the innominate artery when disc oxygenators were used. This difference from our findings may be due to the fact that femoral artery cannulation was used in their studies, whereas in our series the arterial return from the oxygenator was to the ascending aorta. We have, however, confirmed their findings that emboli in the extracorporeal circuit can originate at the air-blood interface of the venous return reservoir of the disc oxygenator, and agree that all fluid added to the circuit should be warmed and introduced without splashing.

It would appear that the spacing between the discs is of importance in the generation of bubbles by disc rotation and elimination of those introduced from the venous reservoir. Our results suggest that this feature accounts for the lower incidence of microbubbles generated by the electrodynamic disc compared with the Kay-Cross disc oxygenators.

The demonstration that the high screen filtration pressure in stored blood, due to altered platelets and leucocytes, is reduced when the blood is filtered through Dacron wool (Swank, 1961) combined with the delay in the development of central nervous system disturbances in animals perfused with filtered blood compared with unfiltered blood (Patterson, Kessler, and Bergland, 1971) suggests these altered platelets and leucocytes may be responsible for cerebral dysfunction. However, ten children perfused with blood having high screen filtration pressure readings did not develop neurological symptoms even though six of them had complicated procedures and prolonged bypass (Ashmore, Svitek, and Ambrose, 1968). It is postulated that a more extensive collateral circulation in these children may have prevented organ damage. Swank and Hain (1952) reduced the effect on the brain of experimental systemic air embolism by inducing cerebral vasodilatation. Induced cerebral vasodilata- tion may be one factor in reducing the incidence of cerebral dysfunction following open hear surgery (Pearson, 1972) in spite of lowered mea perfusion pressures in patients with oxygenatoro known to deliver large quantities of gaseous microemboli.

The use of the 'Sonicaid' has shown that a $\overrightarrow{\mathrm{P}}$ patients having open heart surgery under cardio pulmonary bypass receive gaseous emboli from the oxygenator. The tolerance of patients tot large numbers of emboli is indicated by the absence of any gross psychiatric or neurologicas damage in the majority of patients subjected t this procedure. Nevertheless every attempt shoul be made to reduce to a minimum, if not eliminate completely, gaseous emboli from every source. because of the deleterious effect of small amounts of coronary artery air on myocardial contractilit (Spencer et al., 1965) and the potentially lethat effect on the brain of prolonged perfusions with oxygenators which deliver large numbers of microbubbles in the arterial blood.

One of us (E. G.) was in receipt of a research grar from Newcastle upon Tyne Regional Hospital Board We are grateful to Mr. A. Blesovsky, F.R.C.S., foe permission to publish case reports, to Mr. S. Griffin F.R.C.S., Seaham Hall Hospital, for facilities to investigate patients. We acknowledge the help of the Department of Photography, Newcastle Unive sity, in the preparation of diagrams, The Departmenit of Medical Electronics, Newcastle General Hospita and Mr. A. Evans, B.Sc., of the Department of Surgery, Royal Victoria Infirmary, Newcastle, for assistance and advice. Mr. W. Weir and Mr. R Maltby rendered technical assistance and Miss Thompson typed the manuscript.

\section{REFERENCES}

Ashmore, P. G., Svitek, V., and Ambrose, P. (1968). The incidence and effects of particulate aggregation anfop microembolism in pump-oxygenator systems. $J$. thoran cardiovasc. Surg., 55, 691.

Austen, W. G., and Howry, D. H. (1965). Ultrasound as method to detect bubbles of particulate matter in the arterial line during cardiopulmonary bypass. J. surs Res., 5, 283.

Baglio, C. M., and Hunter, W. C. (1959). Calcific arteriat embolization accompanying commissurotomy. J. thora $\overline{6}$ Surg., 37, 490.

Bass, R. M., and Longmore, D. B. (1969). Cerebral damag during open heart surgery. Nature (Lond.), 222, 30.

Blachy, P. H., and Starr, A. (1964). Post-cardiotomy deliriung Amer. J. Psychiat., 121, 371.

Burbank, A., Ferguson, T. B., and Burford, T. H. (1965 Carbon dioxide flooding of the chest in open-hea surgery. J. thorac. cardiovasc. Surg., 50, 691. 
Caguin, F., and Carter, M. G. (1963). Fat embolization with cardiotomy with the use of cardiopulmonary bypass. $J$. thorac. cardiovasc. Surg., 46, 665.

Carrel, A. (1914). Experimental operations on the orifices of the heart. Ann. Surg., 60, 1.

Cassie, A. B., Riddell, A. G., and Yates, P. O. (1960). Hazard of antifoam emboli from a bubble oxygenator. Thorax, 15, 22.

Ehrenhaft, J. L., and Claman, M. A. (1961). Cerebral complications of open-heart surgery. J. thorac. cardiovasc. Surg., 41, 503.

Evans, E. A., and Wellington, J. S. (1964). Emboli associated with cardiopulmonary bypass. $J$. thorac. cardiovasc. Surg., 48, 323.

Ferguson, T. B., Burbank, A., and Burford, T. H. (1967). The disposable bubble oxygenator. Evaluation of an improved model. Surgery, 61, 260.

Fishman, N. H., Carlsson, E., and Roe, B. B. (1969). The importance of the pulmonary veins in systemic air embolism foll owing open-heart surgery. Surgery, 66, 655

Fries, C. C., Levowitz, B., Adler, S., Cook, A. W., Karlson K. E., and Dennis, C. (1957). Experimental cerebral gas embolism. Ann. Surg., 145, 461.

Gilman, S. (1965). Cerebral disorders after open-heart operations. New Engl. J. Med., 272, 489.

Groves, L. K., and Effler, D. B. (1964). A needle-vent safeguard against systemic air embolus in open-heart surgery. J. thorac. cardiovasc. Surg., 47, 349.

Lawren ce, G. H., McKay, H. A., and Sherensky, R. T. (1971). Effective measures in the prevention of intraoperative aeroembolus. J. thorac. cardiovasc. Surg., 62, 731.

Leading article (1964). Cerebral injury following cardiac operations. Lancet, 1, 89.

Lee, W. H., Krumhaar, D., Fonkalsrud, E. W., Schjeide, O. A., and Maloney, J. V. (1961). Denaturation of plasma proteins as a cause of morbidity and death after intracardiac operations. Surgery, 50, 29.

Lichti, E. L., Simmons, E. M., and Almond, C. A. (1972). Detection of microemboli during cardiopulmonary bypass. Surg. Gynec. Obstet., 134, 977.

Miller, B. J., Gibbon, J. H., Greco, V. F., Cohn, C. H., and Allbritten, F. F. (1953). The use of a vent for the left ventricle as a means of avoiding air embolism to the systemic circulation during open cardiotomy with the maintenance of the cardiorespiratory function of animals by a pump oxygenator. Surg. Forum, 4, 29.

Nichols, H. T., Morse, D. P., and Hirose, T. (1958). Coronary and other air embolization occurring during open cardiac surgery. Surgery, 43, 236.

Nicks, R. (1969). Air embolism in cardiac surgery: incidence and prophylaxis. Aust. N.Z.J. Surg., 38, 328.

Osborn, J. J., Swank, R. L., Hill, J. D., Aguilar, M. J., and Gerbode, F. (1970). Clinical use of a Dacron wool filter during perfusion for open-heart surgery. $J$. thorac. cardiovasc. Surg., 60, 575.
Padula, R. T., Eisenstat, T. E., Bronstein, M. H., and Camishion, R. C. (1971). Intracardiac air following cardiotomy: location, causative factors, and a method for removal. J. thorac cardiovasc. Surg., 62, 736.

Patterson, R. H., and Kessler, J. (1969). Microemboli during cardiopulmonary bypass detected by ultrasound. Surg. Gynec. Obstet., 129, 505.

—_ - and Bergland, R. M. (1971). A filter to prevent cerebral damage during experimental cardiopulmonary bypass. Surg. Gynec. Obstet., 132, 71.

Pearson, D. T. (1972). The use of isoprenaline and alphaadrenergic blockade in open heart surgery. Resuscitation, $1,149$.

Sachdev, N. S., Carter, C. C., Swank, R. L., and Blachly, P. H. (1967). Relationships between post cardiotomy delirium, clinical neurological changes and E.E.G. abnormalities. J. thorac. cardiovasc. Surg., 54, 557.

Sanderson, J. M., Wright, G., and Sims, F. W. (1972). Brain damage in dogs immediately following pulsatile and non-pulsatile blood flows in extracorporeal circulation. Thorax, 27, 275.

Selman, M. W., McAlpine, W. A., and Ratan, R. S. (1967). The effectiveness of various heart-lung machines in the elimination of microbubbles from the circulation. $J$. thorac. cardiovasc. Surg., 53, 613.

Senning, A. (1952). Ventricular fibrillation during extracorporeal circulation used as a method to prevent airembolisms and to facilitate intracardiac operations. Acta chir. scand., Suppl. 171.

Spencer, F. C., Rossi, N. P., Yu, S. C., and Koepke, J. A. (1965). The significance of air embolism during cardiopulmonary bypass. J. thorac. cardiovasc. Surg., 49, 615.

Spencer, M. P., Lawrence, G. H., Thomas, G. I., and Sauvage, L. R. (1969). The use of ultrasonics in the determination of arterial aeroembolism during openheart surgery. Ann. thorac. Surg., 8, 489.

Starr, A. (1960). The mechanism and prevention of air embolism during correction of congenital cleft mitral valve. J. thorac. cardiovasc. Surg., 39, 808.

Swank, R. L. (1961). Alteration of blood on storage. Measurement of adhesiveness of 'ageing' platelets and leucocytes and their removal by filtration. New Engl. J. Med., 265, 728.

Swank, R., and Hain, R. F. (1952). The effect of different sized emboli on the vascular system and parenchyma of the brain. J. Neuropath. exp. Neurol., 11, 280.

Taber, R. E., Maraan, B. M., and Tomatis, L. (1970). Prevention of air embolism during open-heart surgery. A study of the role of trapped air in the left ventricle. Surgery, 68, 685.

Tufo, H. M., Ostfeld, A. M., and Shekelle, R. (1970). Central nervous system dysfunction following openheart surgery. J. Amer. med. Ass., 212, 1333. 